\title{
Mathematical analysis on catalytic dehydrogenation of ethylbenzene using ceramic membranes
}

\author{
Jeffrey C. S. Wu, and Paul K. T. Liu
}

Ind. Eng. Chem. Res., 1992, 31 (1), 322-327 • DOI: 10.1021/ie00001a043

Downloaded from http://pubs.acs.org on November 28, 2008

\section{More About This Article}

The permalink http://dx.doi.org/10.1021/ie00001a043 provides access to:

- Links to articles and content related to this article

- Copyright permission to reproduce figures and/or text from this article 
If this is not the case, only an integer cut added in the master problem.)

Step 8. Formulate and solve the master problem (GBD/OA/ER/AP2 equations) to obtain the set of new binary variables which defines the new flowsheet structure. Set $K=K+1$ and return to step 4 .

\section{Literature Cited}

Beale, E. M. L. Integer Programming. The State of the Art in Numerical Analysis; Academic Press: London, 1977; pp 409-448.

Benders, J. F. Partitioning Procedures for Solving Mired-variables programming problems. Numer. Math. 1962, 4, 238-252.

Biegler, L. T.; Hughes, R. R. Optimization of Propylene Chlorination Process. Comput. Chem. Eng. 1983, 7, 645.

Biegler, L. T.; Cuthrell, J. E. Improved Infeasible Path Optimization for Sequential Modular Simulators. Comput. Chem. Eng. 1985, $9,257$.

Carcotsios, M.; Petrellis, N. C. ACCOPT-An Integrated Software Package for the Optimization of Discrete and Continuous Processes. Presented at the Annual AIChE meeting, San Francisco, 1989.

Douglas, J. M. Conceptual Design of Chemical Processes; McGrawHill Chemical Engineering Series; McGraw-Hill: New York, 1988.

Duran, M. A.; Grossmann, I. E. An Outer-Approximation Algorithm for a Class of Mixed-Integer Nonlinear Programs. Math. Program. 1986, 36, 307-339.

Floudas, C. S.; Aggrawal, A.; Ciric, A. R. Global Optimum Search for Nonconvex NLP and MINLP Problems. Comput. Chem. Eng. $1989,13,1117-1132$.

Geoffrion, A. M. Generalized Benders Decomposition. J. Optim. Theory Appl. 1972, 10 (4), 237-260.

Grossmann, I. E. MINLP Optimization Strategies and Algorithms for Process Synthesis. Proceedings FOCAPD'89; Siirola et al., Eds.; Elsevier: Amsterdam, 1990; p 105.

Gupta, O. K. Branch and Bound Experiments in Nonlinear Integer Programming. Ph.D. Thesis, Purdue University, 1980.

Han, S. P. A Globally Convergent Method for Nonlinear Programming. J. Optim. Theory Appl. 1977, 22, 297.

Harsh, M. G.; Saderne, P.; Biegler, L. T. A Mixed Integer Flowsheet Optimization for Process Retrofits: The Debottlenecking Problem. Comput. Chem. Eng. 1989, 13, 947-957.

Kocis, G. R.; Grossmann, I. E. Relaxation Strategy for the Structural Optimization of Process Flowsheets. Ind. Eng. Chem. Res. 1987, 26 (9), 1869-1880.

Kocis, G. R.; Grossmann, I. E. A Modelling/Decomposition Strategy for MINLP Optimization of Process Flowsheets. Comput. Chem. Eng. 1989, 13, 797-819.

Kravanja, Z.; Grossmann, I. E. PROSYN-An MINLP Synthesizer. Comput. Chem. Eng. 1990, 14, 1363.

Lang, Y. D.; Biegler, L. T. A Unified Algorithm for Flowsheet Optimization. Comput. Chem. Eng. 1987, 11, 143.

Marsten, R. User's Manual for ZOOM/XMP; The Department of Management Information Systems, University of Arizona: Tucson, 1986.

Powell, M. J. D. The Convergence of Variable Matric Methods for Nonlinear Constrained Optimization Calculations. Nonlinear Programming; Academic Press: London, 1978.

Schrage, L. Linear Programming Models with LINDO; The Scientific Press: 1983.

Viswanathan, J.; Grossmann, I. E. A Combined Penalty Function and Outer-Approximation Method for MINLP Optimization. Comput. Chem. Eng. 1990, 14, 769.

Received for review May 2, 1991 Accepted September 27, 1991

\title{
Mathematical Analysis on Catalytic Dehydrogenation of Ethylbenzene Using Ceramic Membranes
}

\author{
Jeffrey C. S. Wu* and Paul K. T. Liu \\ Alcoa Separations Technology, Inc., Warrendale, Pennsylvania 15086
}

Ceramic membranes capable of performing Knudsen separations were discussed extensively in the literature as a potential candidate for membrane reactor processes. A mathematical model is employed to evaluate the performance of a membrane reactor for the catalytic dehydrogenation of ethylbenzene to styrene. The model previously discussed in the literature has been modified to include side reactions for estimating product selectivities. According to our analysis in a selected case study, an increase $(\geq 5 \%)$ in styrene yield over the thermodynamic limit is achieved by a hybrid system, i.e., a fixed bed reactor in conjunction with a membrane reactor. The proposed membrane reactor shows a different behavior in the generation of key side products, i.e., benzene and toluene. The side reaction for toluene is inhibited as a result of the selective removal of hydrogen, while the generation of benzene continues at a reduced rate.

A commercially available ceramic membrane with a multiple-layer, composite, asymmetric structure is selected in this study. It can deliver gas separations according to Knudsen diffusion. Figure 1 shows a schematic of the selected membrane reactor. The membrane tube is packed with granular catalysts. Reactant is fed in the tubular side, while inert purge or vacuum can be applied in the shell side. The permeable membrane can preferentially remove one of the products (e.g., hydrogen in dehydrogenation) and, then, enhance the conversion.

Several mathematical models describing the performance of membrane reactors were developed in the literature (Mohan and Govind, 1986, 1988 a-c; Itoh et al., 1984, 1985; Itoh, 1987, Itoh and Govind, 1989a,b; Sun and Khang, $1988,1990)$. Enhanced conversions under various operating conditions were discussed in detail. However, the effect of membrane reactors on product selectivities has not been addressed because none of these models have 


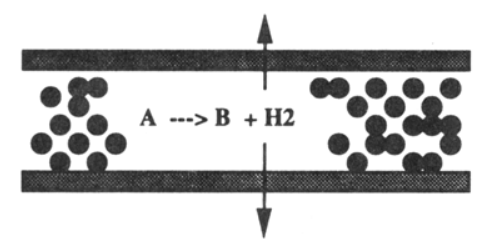

Figure 1. Membrane reactor.

considered side reactions. The model has been modified to include side reactions occurring in ethylbenzene dehydrogenation to styrene. Yields from the side reactions, e.g., benzene (BEN) and toluene (TOL), have been analyzed for a proposed hybrid system, i.e., a fixed bed reactor in conjunction with a membrane reactor.

\section{Mathematical Model}

Assumptions. This model simulates the operation under an isothermal, steady-state condition. The ideal gas behavior is assumed since most dehydrogenation reactions are carried out at high temperatures $\left(400-700^{\circ} \mathrm{C}\right)$ and low pressures $(<2$ atm). Plug flows are assumed in both tube and shell sides. Radial dispersion in the tube and shell sides is negligible. Like most models presented in the literature, no intraparticle mass transfer resistance in the catalyst is included. Gas separation through the microporous ceramic membrane follows ideal Knudsen diffusion; i.e., the separation factor is inversely proportional to the square root of the molecular weight ratio.

Rate Equations. The rate expressions of ethylbenzene dehydrogenation have been obtained from the literature (Wenner and Dybdal, 1948; Sheel and Crowe, 1969; Clough and Ramirez, 1976; Sheppard and Maier, 1986). Depending on catalysts and operating conditions, many side reactions could possibly occur. Carbon deposition and removal are excluded here because the resulting rate of change in the catalyst activity is much slower than those of dehydrogenation reactions. Reactions for minor side products, e.g., ethane, propane, and propylene, are ignored (Sheel and Crowe, 1969). Most literature (Wenner and Dybdal, 1948; Sheel and Crowe, 1969; Sheppard and Maier, 1986) suggested that the main reaction, i.e., ethylbenzene (EB) to styrene (ST), and the five side reactions were adequate to describe the output products in typical styrene production processes, which are listed as follows:

main reaction

$$
\begin{gathered}
\mathrm{C}_{6} \mathrm{H}_{5} \mathrm{C}_{2} \mathrm{H}_{5} \leftrightarrow \mathrm{C}_{6} \mathrm{H}_{5} \mathrm{C}_{2} \mathrm{H}_{3}+\mathrm{H}_{2} \\
\text { rate }=k_{1}\left(P_{\mathrm{EB}}-\frac{P_{\mathrm{ST}} P_{\mathrm{H}_{2}}}{K_{\mathrm{p}}}\right)=k_{1}\left(P_{\mathrm{EB}}-P_{\mathrm{EB}, \mathrm{eq}}\right) \\
K_{\mathrm{p}}=\frac{P_{\mathrm{ST}, \mathrm{eq}} P_{\mathrm{H}_{2}, \mathrm{eq}}}{P_{\mathrm{EB}, \mathrm{eq}}}
\end{gathered}
$$

side reactions

$$
\begin{gathered}
\mathrm{C}_{6} \mathrm{H}_{5} \mathrm{C}_{2} \mathrm{H}_{5}+\mathrm{H}_{2} \rightarrow \mathrm{C}_{6} \mathrm{H}_{5} \mathrm{CH}_{3}+\mathrm{CH}_{4} \\
\text { rate }=k_{2}\left(P_{\mathrm{EB}} P_{\mathrm{H}_{2}}\right) \\
\mathrm{C}_{6} \mathrm{H}_{5} \mathrm{C}_{2} \mathrm{H}_{5} \rightarrow \mathrm{C}_{6} \mathrm{H}_{6}+\mathrm{C}_{2} \mathrm{H}_{4} \\
\text { rate }=k_{3} P_{\mathrm{EB}} \\
1 / 2 \mathrm{C}_{2} \mathrm{H}_{4}+\mathrm{H}_{2} \mathrm{O} \rightarrow \mathrm{CO}+2 \mathrm{H}_{2} \\
\text { rate }=k_{4}\left(P_{\mathrm{H}_{2} \mathrm{O}} P_{\mathrm{C}_{2} \mathrm{H}_{4}}\right) \\
\mathrm{CH}_{4}+\mathrm{H}_{2} \mathrm{O} \rightarrow \mathrm{CO}+3 \mathrm{H}_{2} \\
\text { rate }=k_{5}\left(P_{\mathrm{H}_{2} \mathrm{O}} P_{\mathrm{CH}_{4}}\right) \\
\mathrm{CO}+\mathrm{H}_{2} \mathrm{O} \rightarrow \mathrm{CO}_{2}+\mathrm{H}_{2} \\
\text { rate }=k_{6}\left(P_{\mathrm{t}} / T^{3}\right)\left(P_{\mathrm{H}_{2} \mathrm{O}} P_{\mathrm{CO}}\right)
\end{gathered}
$$

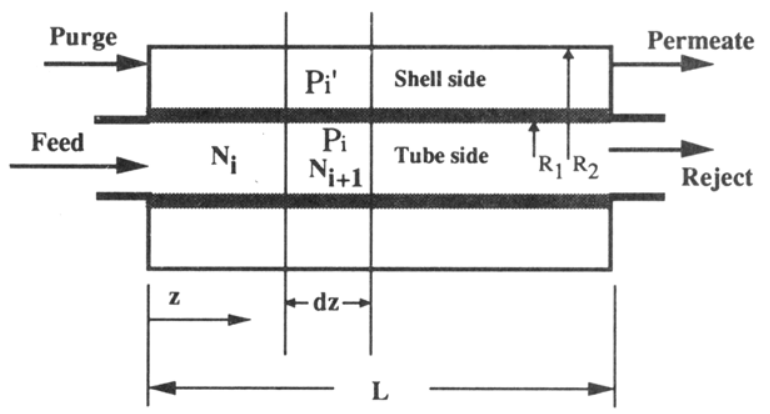

Figure 2. Schematic of material balance in membrane reactor.

All side reactions theoretically are also reversible and can reach equilibria if an infinite contact time is given. The side reaction rates, however, are much slower than the main one (Sheppard and Maier, 1986). In addition, our simulation with a prime purpose for the styrene production has been confined in the conditions where the side reactions are far from equilibria. The reverse rates of the side reactions are negligible in this model. The effective permeability is calculated according to Knudsen diffusion as follows:

$$
\begin{aligned}
K_{i} & =\frac{2 r \epsilon_{\mathrm{p}}}{3 \tau R T d}\left(8000 R \frac{T}{\pi M_{i}}\right)^{1 / 2} \\
i & =\mathrm{EB}, \mathrm{ST}, \mathrm{H}_{2}, \mathrm{H}_{2} \mathrm{O}, \mathrm{TOL}, \mathrm{BEN}, \mathrm{CH}_{4}, \mathrm{C}_{2} \mathrm{H}_{4}, \mathrm{CO}, \mathrm{CO}_{2}
\end{aligned}
$$

Effective permeability is dependent on the pore size, porosity, and tortuosity of the membrane structure in addition to temperature and molecular weight. In the case of ethylbenzene dehydrogenation, the separation factor of hydrogen to ethylbenzene is about 7.3.

Material Balance. A set of differential equations for each component can be derived through the shell material balance shown in Figure 2.

tube side

$$
\begin{aligned}
& \left.\pi R_{1}^{2} N_{\mathrm{A}}\right|_{z+\Delta z}-\left.\pi R_{1}^{2} N_{\mathrm{A}}\right|_{z}+2 \pi R_{1} \Delta z K_{\mathrm{A}}\left(P_{\mathrm{A}}-P_{\mathrm{A}}^{\prime}\right) \pm \\
& \left(\text { reaction rates) } \pi R_{1}^{2} \Delta z=0\right. \\
& \therefore \quad \frac{\mathrm{d} N_{\mathrm{A}}}{\mathrm{d} z}+\frac{2 K_{\mathrm{A}}}{R_{1}}\left(P_{\mathrm{A}}-P_{\mathrm{A}}^{\prime}\right) \pm \text { reaction rates }=0
\end{aligned}
$$

The " \pm " sign in the equation is determined for each component as follows: " + " means that species are consumed in reactions; "-" means species are generated in reactions. Material balance for each component is described as follows:

$$
\text { EB: } \begin{array}{r}
\frac{\mathrm{d} N_{\mathrm{EB}}}{\mathrm{d} z}+\frac{2 K_{\mathrm{EB}}}{R_{1}}\left(P_{\mathrm{EB}}-P_{\mathrm{EB}}{ }^{\prime}\right)+k_{1}\left(\mathrm{P}_{\mathrm{EB}}-\frac{P_{\mathrm{ST}} P_{\mathrm{H}_{2}}}{K_{\mathrm{p}}}\right)+ \\
k_{2}\left(P_{\mathrm{EB}} P_{\mathrm{H}_{2}}\right)+k_{3} P_{\mathrm{EB}}=0
\end{array}
$$

ST:

$$
\frac{\mathrm{d} N_{\mathrm{ST}}}{\mathrm{d} z}+\frac{2 K_{\mathrm{ST}}}{R_{1}}\left(P_{\mathrm{ST}}-P_{\mathrm{ST}}{ }^{\prime}\right)-k_{1}\left(P_{\mathrm{EB}}-\frac{P_{\mathrm{ST}} P_{\mathrm{H}_{2}}}{K_{\mathrm{p}}}\right)=0
$$$$
\mathrm{H}_{2}: \frac{\mathrm{d} N_{\mathrm{H}_{2}}}{\mathrm{~d} z}+\frac{2 K_{\mathrm{H}_{2}}}{R_{1}}\left(P_{\mathrm{H}_{2}}-P_{\mathrm{H}_{2}}{ }^{\prime}\right)-k_{1}\left(\mathrm{P}_{\mathrm{EB}}-\frac{P_{\mathrm{ST}_{\mathrm{T}} P_{\mathrm{H}_{2}}}}{K_{\mathrm{p}}}\right)+
$$$$
k_{2}\left(P_{\mathrm{EB}} P_{\mathrm{H}_{2}}\right)-2 k_{4}\left(P_{\mathrm{H}_{2} \mathrm{O}} P_{\mathrm{C}_{2} \mathrm{H}_{4}}\right)-3 k_{5}\left(P_{\mathrm{H}_{2} \mathrm{O}} P_{\mathrm{CH}_{4}}\right)-
$$$$
k_{6} \frac{P_{\mathrm{t}}}{T^{3}}\left(P_{\mathrm{H}_{2} \mathrm{O}} P_{\mathrm{CO}}\right)=0
$$ 


$$
\begin{aligned}
& \mathrm{H}_{2} \mathrm{O}: \frac{\mathrm{d} N_{\mathrm{H}_{2} \mathrm{O}}}{\mathrm{d} z}+\frac{2 K_{\mathrm{H}_{2} \mathrm{O}}}{R_{1}}\left(P_{\mathrm{H}_{2} \mathrm{O}}-P_{\mathrm{H}_{2} \mathrm{O}^{\prime}}\right)+k_{4}\left(P_{\mathrm{H}_{2} \mathrm{O}} P_{\mathrm{C}_{2} \mathrm{H}_{4}}\right)+ \\
& k_{5}\left(P_{\mathrm{H}_{2} \mathrm{O}} P_{\mathrm{CH}_{4}}\right)+k_{6} \frac{P_{\mathrm{t}}}{T^{3}}\left(P_{\mathrm{H}_{2} \mathrm{O}} P_{\mathrm{CO}}\right)=0 \\
& \text { TOL: } \frac{\mathrm{d} N_{\mathrm{TOL}}}{\mathrm{d} z}+\frac{2 K_{\mathrm{TOL}}}{R_{1}}\left(P_{\mathrm{TOL}}-P_{\mathrm{TOL}}{ }^{\prime}\right)-k_{2}\left(P_{\mathrm{EB}} P_{\mathrm{H}_{2}}\right)=0 \\
& \mathrm{BEN}: \frac{\mathrm{d} N_{\mathrm{BEN}}}{\mathrm{d} z}+\frac{2 K_{\mathrm{BEN}}}{R_{1}}\left(P_{\mathrm{BEN}}-P_{\mathrm{BEN}}{ }^{\prime}\right)-k_{3} P_{\mathrm{EB}}=0 \\
& \mathrm{CH}_{4}: \frac{\mathrm{d} N_{\mathrm{CH}_{4}}}{\mathrm{~d} z}+\frac{2 K_{\mathrm{CH}_{4}}}{R_{1}}\left(P_{\mathrm{CH}_{4}}-P_{\mathrm{CH}_{4}}{ }^{\prime}\right)-k_{2}\left(P_{\mathrm{EB}} P_{\mathrm{H}_{2}}\right)+ \\
& k_{5}\left(P_{\mathrm{H}_{2} \mathrm{O}} P_{\mathrm{CH}_{4}}\right)=0 \\
& \mathrm{C}_{2} \mathrm{H}_{4}: \frac{\mathrm{d} N_{\mathrm{C}_{2} \mathrm{H}_{4}}}{\mathrm{~d} z}+\frac{2 K_{\mathrm{C}_{2} \mathrm{H}_{4}}}{R_{1}}\left(P_{\mathrm{C}_{2} \mathrm{H}_{4}}-P_{\mathrm{C}_{2} \mathrm{H}_{4}{ }^{\prime}}\right)-k_{3} P_{\mathrm{EB}}+ \\
& \frac{1}{2} k_{4}\left(P_{\mathrm{H}_{2} \mathrm{O}} P_{\mathrm{C}_{2} \mathrm{H}_{4}}\right)=0 \\
& \mathrm{CO}: \frac{\mathrm{d} N_{\mathrm{CO}}}{\mathrm{d} z}+\frac{2 K_{\mathrm{CO}}}{R_{1}}\left(P_{\mathrm{CO}}-P_{\mathrm{CO}}\right)-k_{4}\left(P_{\mathrm{H}_{2} \mathrm{O}} P_{\mathrm{C}_{2} \mathrm{H}_{4}}\right)- \\
& k_{5}\left(P_{\mathrm{H}_{2} \mathrm{O}} P_{\mathrm{CH}_{4}}\right)+k_{6} \frac{P_{\mathrm{t}}}{T^{3}}\left(P_{\mathrm{H}_{2} \mathrm{O}} P_{\mathrm{CO}}\right)=0 \\
& \mathrm{CO}_{2}: \frac{\mathrm{d} N_{\mathrm{CO}_{2}}}{\mathrm{~d} z}+\frac{2 K_{\mathrm{CO}_{2}}}{R_{1}}\left(P_{\mathrm{CO}_{2}}-P_{\mathrm{CO}_{2}}{ }^{\prime}\right)-k_{6} \frac{P_{\mathrm{t}}}{T^{3}}\left(P_{\mathrm{H}_{2} \mathrm{O}} P_{\mathrm{CO}}\right)=0
\end{aligned}
$$

shell side

$$
\begin{aligned}
& \pi\left(R_{2}^{2}-R_{1}^{2}\right) N_{\mathrm{Al} z+\Delta z}^{\prime}-\left.\pi\left(R_{2}^{2}-R_{1}^{2}\right) N_{\mathrm{A}}^{\prime}\right|_{z}- \\
& 2 \pi R_{1} \Delta z K_{\mathrm{A}}\left(P_{\mathrm{A}}-P_{\mathrm{A}}{ }^{\prime}\right)=0 \\
& \therefore \quad \frac{\mathrm{d} N_{\mathrm{A}}{ }^{\prime}}{\mathrm{d} z}-\frac{2 R_{1} K_{\mathrm{A}}}{R_{2}{ }^{2}-R_{1}{ }^{2}}\left(P_{\mathrm{A}}-P_{\mathrm{A}}{ }^{\prime}\right)=0
\end{aligned}
$$

Similarly, an equation for each component can be derived. $\frac{\mathrm{d} N_{i}^{\prime}}{\mathrm{d} z}-\frac{2 K_{i} R_{1}}{R_{2}{ }^{2}-R_{1}{ }^{2}}\left(P_{i}-P_{i}^{\prime}\right)=0 \quad i=\mathrm{EB}, \mathrm{ST}, \mathrm{H}_{2}, \mathrm{H}_{2} \mathrm{O}$, TOL, BEN, $\mathrm{CH}_{4}, \mathrm{C}_{2} \mathrm{H}_{4}, \mathrm{CO}$, and $\mathrm{CO}_{2}$

The relationship between total and partial pressures of each component can be expressed by the following equations:

tube side

$P_{\mathrm{i}}=\left(N_{i} / \sum N_{i}\right) P_{\mathrm{t}}$ $i=\mathrm{EB}, \mathrm{ST}, \mathrm{H}_{2}, \mathrm{H}_{2} \mathrm{O}$, TOL, $\mathrm{BEN}, \mathrm{CH}_{4}, \mathrm{C}_{2} \mathrm{H}_{4}, \mathrm{CO}$, and $\mathrm{CO}_{2}$

shell side

$$
P_{i}^{\prime}=\left(N_{i}^{\prime} / \sum N_{i}^{\prime}\right) P_{\mathrm{s}} \quad i=\mathrm{EB}, \mathrm{ST}, \mathrm{H}_{2}, \mathrm{H}_{2} \mathrm{O}, \mathrm{TOL},
$$

The Ergun equation has been used to calculate the pressure drop of the packed bed in the tube side. Annulus momentum balance has been performed to determine the pressure drop in the shell side (Bird et al., 1960) as follows:

$$
\begin{gathered}
-\frac{\mathrm{d} P_{\mathrm{t}}}{\mathrm{d} z}=\frac{150 \mu v_{z}}{D_{\mathrm{p}}{ }^{2}} \frac{(1-\epsilon)^{2}}{\epsilon^{3}}+\frac{1.75 \rho v_{z}^{2}}{\mathrm{D}_{\mathrm{p}}}\left(\frac{1-\epsilon}{\epsilon^{3}}\right) \\
\text { for tube side total pressure drop } \\
-\frac{\mathrm{d} P_{\mathrm{s}}}{\mathrm{d} z}=\frac{8 \mu v_{z}^{\prime} \ln \left(R_{1} / R_{2}\right)}{\begin{array}{c}
\ln \left(R_{1} / R_{2}\right)\left(R_{2}{ }^{2}+R_{1}{ }^{2}\right)+\left(R_{2}{ }^{2}-R_{1}{ }^{2}\right) \\
\text { for shell side total pressure drop }
\end{array}}
\end{gathered}
$$

where

$$
\begin{aligned}
v_{z} & =0.0224 \sum N_{i}(T / 273) \\
v_{z}{ }^{\prime} & =0.0224 \sum N_{i}^{\prime}(T / 273)
\end{aligned}
$$

Density $(\rho)$ and viscosity $(\mu)$ of the gaseous mixture required by these equations are estimated by the correspondent state and Lucas mixing rule (Reid et al., 1987).

Boundary Conditions. The boundary conditions for the reactor are listed as follows:

$$
\begin{aligned}
& \text { at } z=0: \quad N_{\mathrm{EB}}=N_{\mathrm{EB}, 0} \\
& N_{\mathrm{H}_{2} \mathrm{O}}=N_{\mathrm{H}_{2} \mathrm{O}, 0} \\
& N_{\mathrm{ST}}, N_{\mathrm{H}_{2}}, N_{\mathrm{TOL}}, N_{\mathrm{BEN}}, N_{\mathrm{CH}_{4}}, N_{\mathrm{C}_{2} \mathrm{H}_{4}}, N_{\mathrm{CO}} \\
& \text { and } N_{\mathrm{CO}_{2}}=0 \text { for the tube side (38) } \\
& N_{\mathrm{H}_{2} \mathrm{O}^{\prime}}=N_{\mathrm{H}_{2} \mathrm{O}, 0^{\prime}} \\
& N_{\mathrm{EB}^{\prime}}{ }^{\prime}, N_{\mathrm{ST}^{\prime}}, N_{\mathrm{H}_{2}}{ }^{\prime}, N_{\mathrm{TOL}}{ }^{\prime}, N_{\mathrm{BEN}}{ }^{\prime}, N_{\mathrm{CH}_{4}}{ }^{\prime}, N_{\mathrm{C}_{2} \mathrm{H}_{4}}{ }^{\prime}, N_{\mathrm{CO}^{\prime}} \text {, } \\
& \text { and } N_{\mathrm{CO}_{2}{ }^{\prime}}=0 \quad \text { for the shell side (40) } \\
& \text { at } z=L \text { : } \\
& P_{\mathrm{t}}=P_{\mathrm{t} L} \text { (pressure selected at exit) for the tube side }
\end{aligned}
$$$$
P_{\mathrm{8}}=
$$$$
P_{\mathrm{s} L} \text { (pressure selected at exit) for the shell side }
$$

Analysis of variables.

Independent variable: $z$

State variables: $N_{\mathrm{EB}}, N_{\mathrm{ST}}, N_{\mathrm{H}_{2}}, N_{\mathrm{H}_{2} \mathrm{O}}, N_{\mathrm{TO}}, N_{\mathrm{BEN}}, N_{\mathrm{CH}}$, $N_{\mathrm{C}_{2} \mathrm{H}_{4}}, N_{\mathrm{CO}}, N_{\mathrm{CO}_{2}}, N_{\mathrm{EB}^{\prime}}, N_{\mathrm{ST}^{\prime}}, N_{\mathrm{H}_{2}}{ }^{\prime}, N_{\mathrm{H}_{2}{ }^{\prime}}, N_{\mathrm{TOL}}{ }^{\prime}, N_{\mathrm{BEN}}$, $N_{\mathrm{CH}_{4}}{ }^{\prime}, N_{\mathrm{C}_{2} \mathrm{H}_{4}}, N_{\mathrm{CO}^{\prime}}, N_{\mathrm{CO}_{2}}{ }^{\prime}, P_{\mathrm{t}}$, and $P_{\mathrm{s}}$ (the total number is 22)

Differential equations: 22 (eqs $17-26,29,32$, and 33 )

Boundary conditions: 22 (eqs $36-42$ )

Solutions for Mathematical Model. Since the numbers of boundary conditions and state variables are equal to that of the equations, one and only one unique solution is obtained. FORTRAN programming and a subroutine (D02HAE) in the NAG (Numerical Algorithms Group, 1987) library have been used to solve this model numerically.

The physical parameters for the membrane reactor selected in this study are based on a commercial membrane tube. They are listed in Table I. The product yields are defined as follows:

styrene yield $=\frac{\text { styrene }_{\text {Rej }}+\text { styrene }_{\text {Perm }}}{\mathrm{EB}_{\text {Feed }}} \times 100 \%$

(same for toluene and benzene).

The mathematical equations developed here can be described by the five dimensionless groups detailed in Table II. The Damkohler $(D a)$ number represents the contact time, determined by flow rate, or reactor geometry. $\Delta$ is the ratio of permeation to reaction rates. It compares the rate of molecule diffusion through membranes to the molecule consumption or generation by the reaction. $C t$ is the ratio of the inert dilution to the feed reactant, i.e., $\mathrm{H}_{2} \mathrm{O}$ to ethylbenzene ratio. $C s$ is the ratio of the inert purge (i.e., $\mathrm{H}_{2} \mathrm{O}$ ) to feed ethylbenzene in the shell side. $\mathrm{Pr}$ is the shell to tube pressure ratio which controls the flow distribution between permeate and reject.

\section{Results and Discussion}

Typical Behaviors of Membrane Reactors. Figure 3 illustrates the fundamental concept of the performance of a membrane reactor. The two dotted lines represent the maximum styrene yield determined by the operating condition. The lower line indicates the maximum styrene 
Table I. Physical Parameters of Commercial Ceramic Membrane and Catalysts Used in This Study

$\begin{array}{ll}\text { tube diameter } & 0.634 \mathrm{~cm} \\ \text { shell diameter } & 1.574 \mathrm{~cm} \\ \text { pore diameter (membrane) } & 40 \AA \\ \text { membrane thickness } & 5 \mu \mathrm{m} \\ \text { tortuosity (membrane) } & 2.95 \\ \text { membrane porosity } & 0.5 \\ \text { length } & 25.0 \mathrm{~cm} \\ \text { catalyst size } & 2.0 \mathrm{~mm} \\ \text { packed bed porosity } & 0.6\end{array}$

Table II. Dimensionless Groups

\begin{tabular}{|c|c|}
\hline $\begin{array}{l}\text { dimensionless } \\
\text { groups }\end{array}$ & physical meanings \\
\hline $\begin{array}{l}D a=k_{1} P_{\mathrm{t}} L / N_{\mathrm{EB}} \\
\Delta=2 K_{\mathrm{H}_{2}} / k_{1} R_{1} \\
C t=N_{\mathrm{H}_{2} \mathrm{O}} / N_{\mathrm{EB}} \\
C s=N_{\mathrm{HoO}}^{\prime} / N_{\mathrm{EB}} \\
\operatorname{Pr}=P_{\mathrm{s}} / P_{\mathrm{t}}\end{array}$ & $\begin{array}{l}\text { reactor length, flow rate, contact time } \\
\left(\mathrm{H}_{2} \text { permeability)/(reaction rate), (mem }\right. \\
\text { surface area) } / \text { (membrane reactor volu } \\
\text { dilution ratio } \\
\text { inert purge rate at shell side } \\
\text { pressure ratio of shell and tube }\end{array}$ \\
\hline 100 & Mudmum Yield Bened on Permoats Componition \\
\hline 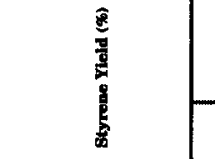 & Id Bared an Feed-ride Compoed tion \\
\hline
\end{tabular}

Da (contect time, Reactor volume/fow rate)

Figure 3. Enhanced styrene yield in a membrane reactor.

yield based upon the feed composition, pressure, and temperature, representing the maximum yield achievable by a conventional packed bed reactor. The upper line indicates the maximum styrene yield determined by a given set of feed and operating conditions, representing the upper limit achievable by a membrane reactor. For a simple dehydrogenation, the upper line is determined by the thermodynamics based upon the shell side composition, pressure, and temperature at the exit of the reactor. The solid curve indicates the styrene yield achieved by a membrane reactor with a function of the $D a$ number. Along with the increase of $D a$ number, the styrene yield increases to a maximum level at which the rate of ethylbenzene to styrene is equal to its reversed rate. The difference between the solid curve and the lower dotted line indicates the enhancement potentially achievable by a membrane reactor.

Effects of Membrane Permeability and Reaction Rate. The performance of a membrane reactor is also controlled by permeability and reaction rate. Permeability is the characteristics of a given membrane, which could be modified through membrane layer configuration or its porous structure. (The separation factor of $\mathrm{H}_{2}$ to ethylbenzene still follows the Knudsen diffusion, i.e., 7.3.) Reaction rate is determined by the activity of the catalyst used. For a given catalyst, the reaction rate varies with the reaction temperature. These two factors are closely affiliated and are combined into a single dimensionless term, $\Delta$.

In the ethylbenzene dehydrogenation, $\Delta$ is expressed by the ratio of the hydrogen permeability to the dehydrogenation reaction rate. Physically it means the rate ratio of removing to generating hydrogen in the reactor. Figure 4 presents the effect of $\Delta$ on the enhanced styrene yield over the calculated maximum yield achievable by the

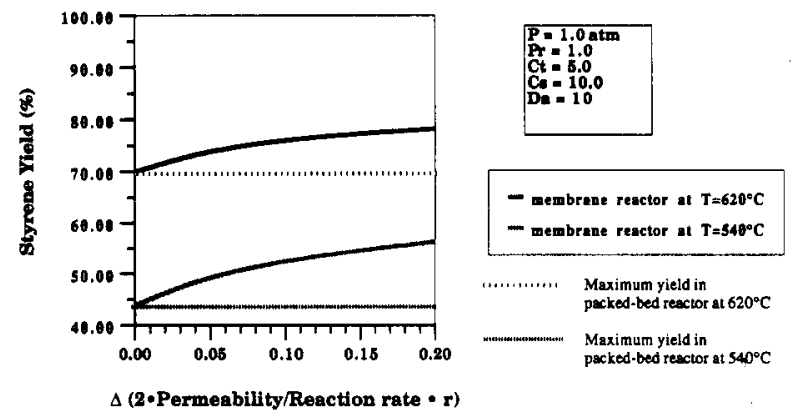

Figure 4. Inert membrane packed with catalysts: effect of permeability.
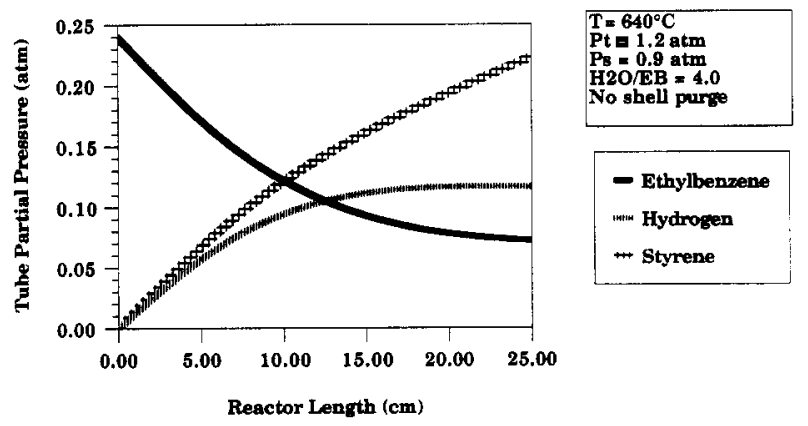

Figure 5. Partial pressure profiles in tube side of membrane reactor.

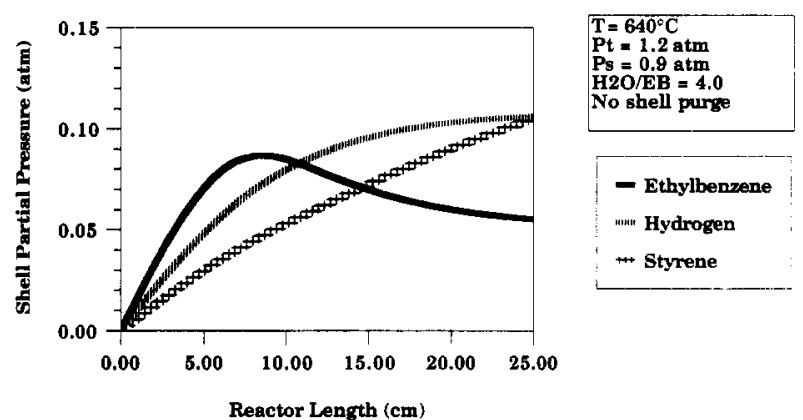

Figure 6. Partial pressure profiles in shell side of membrane reactor.

packed bed. When $\Delta$ is zero, i.e., use of a nonpermeable wall, no enhancement is expected. When $\Delta$ increases, the enhancement increases via hydrogen removal. For a given reaction rate (i.e., a given catalyst operated at a given temperature), the enhanced styrene yield is proportional to the permeability of a membrane. Eventually, the enhancement reaches a theoretical upper limit, corresponding to the calculated maximum styrene yield based upon the shell side condition.

Since gas separations in the ceramic membrane follow Knudsen diffusion, increase in permeability causes not only the enhanced removal of hydrogen but also the increased loss of ethylbenzene to the shell side, which is undesirable. One way to minimize the loss is the use of a hybrid reactor, which is discussed in the next section.

Concept of Hybrid System. One of the challenges in a membrane reactor is to minimize the reactant loss to the shell side. Since hydrogen is selectively removed to the shell side, hydrogenation (i.e., styrene back to ethylbenzene) should be avoided with no catalyst presence in the shell side. Therefore, the reactant prematurely leaked to the shell side cannot be dehydrogenated to the product due to the lack of catalysts in the reactor configuration. Figure 5 presents the partial pressure profiles in the tube side of a membrane reactor. In the beginning section, substantial ethylbenzene is unreacted. Its partial pressure is so high that significant ethylbenzene can diffuse to the 


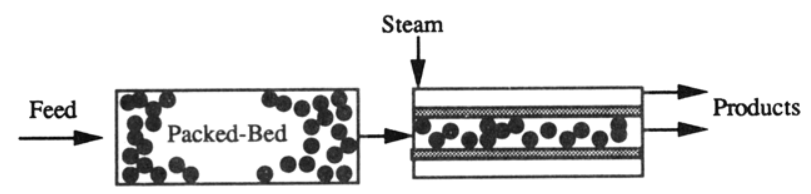

Figure 7. Schematic of add-on stage membrane reactors.

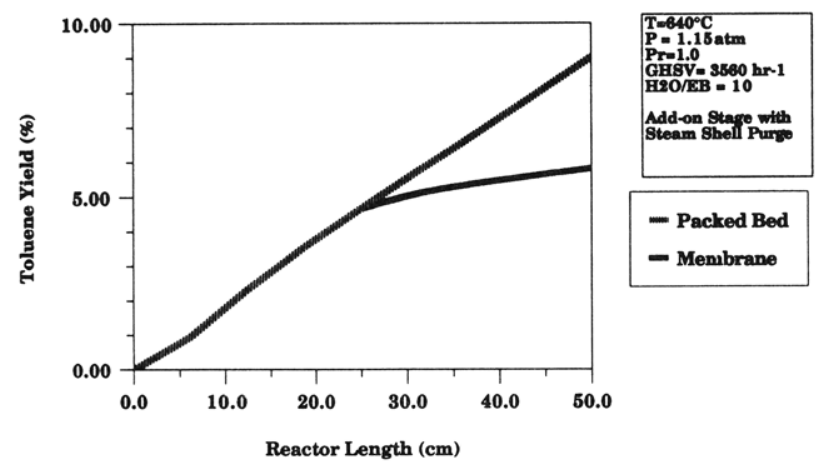

Figure 8. Toluene yield in add-on stage of membrane reactor.

shell side as shown in Figure 6. The partial pressure of ethylbenzene in the shell side is higher than those of hydrogen and styrene in the beginning section. This indicates the significant loss of ethylbenzene, which is undesirable. To maximize the enhancement, one should seek a maximum hydrogen removal from the tube side. Unfortunately, in a single-stage membrane reactor, the driving force resulting from the ethylbenzene partial pressure is always high in the beginning of the reactor.

In order to maximize hydrogen removal and minimize ethylbenzene loss in the tube side, the combination of a packed bed and a membrane reactor has been proposed. Figure 7 illustrates this concept. With a packed bed reactor as a first stage, ethylbenzene can be sufficiently converted to styrene and hydrogen. Then, the out product is sent to a membrane reactor. $\mathrm{H}_{2}$ can be preferentially removed once the stream enters the membrane reactor. Also, part of the ethylbenzene is already consumed in the first stage so that the loss will be reduced in the secondstage membrane reactor. This concept with an add-on stage of the membrane reactor can be implemented via retrofitting the existing industrial processes. In the following section, the behavior of the main and side reactions in the add-on membrane reactor is discussed. All the simulations are based upon the rate expressions listed in eqs $1-13$.

Yields of Side Products. Toluene and benzene are the two key side products in ethylbenzene dehydrogenation. If a membrane reactor is installed after a packed bed, the yields of toluene and benzene can be changed significantly. Performance of a packed bed reactor as a second stage has been also simulated for comparison. The dehydrogenation achieved by the first stage approximates the maximum styrene level in this simulation. Subsequently, the performance difference between the conventional and the membrane reactors in the second stage is determined via the developed model.

Figure 8 gives the variation of toluene yield in the packed bed and membrane reactors. With an add-on packed bed reactor, the toluene generation continues to increase along with the length of the reactor. On the other hand, the toluene levels off in the add-on membrane reactor. Toluene is generated by hydrogenolysis of the ethyl group in ethylbenzene molecules, and its rate is dependent on the partial pressure of $\mathrm{H}_{2}$ (eqs 4 and 5). This side reaction is inhibited by reducing the $\mathrm{H}_{2}$ partial pressure in the membrane reactor. Therefore, the toluene yield is

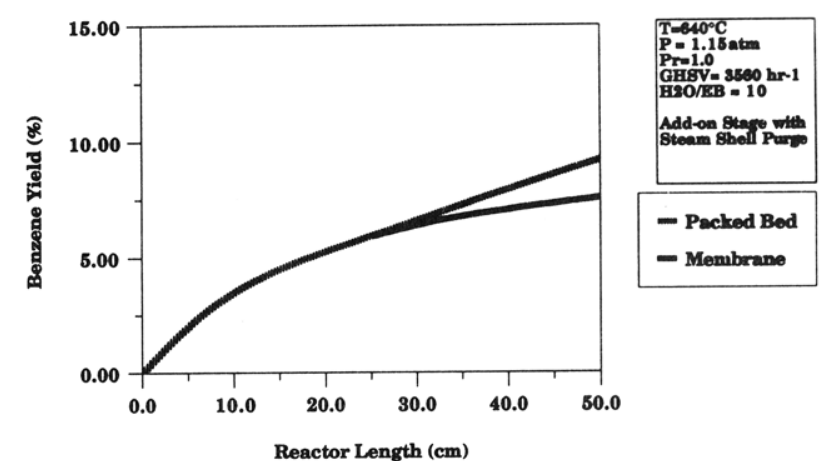

Figure 9. Benzene yield in add-on stage of membrane reactor.

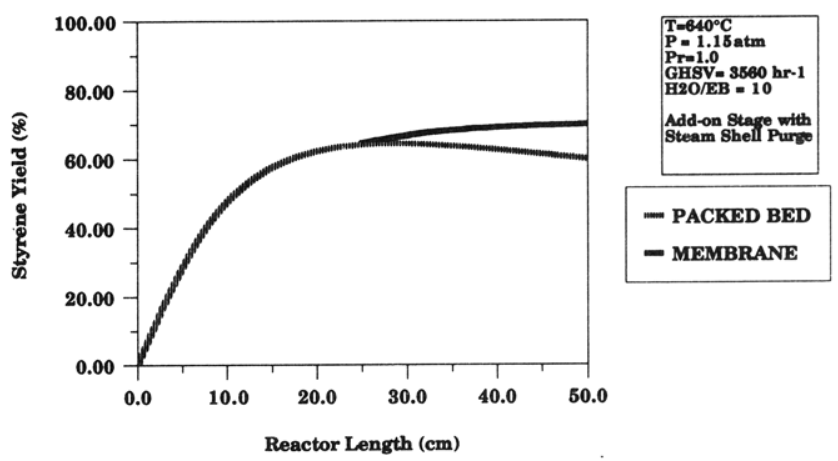

Figure 10. Styrene yield in add-on stage of membrane reactor.

kept near the level of the previous packed bed reactor.

Figure 9 shows the benzene yield vs reactor length. The increase of benzene is slower in the add-on membrane reactor. The mechanism for benzene generation is different from that of toluene. Benzene is generated from the scission of the ethyl group from ethylbenzene, and its rate is dependent on the partial pressure of ethylbenzene (eqs 6 and 7). Removing $\mathrm{H}_{2}$ in the membrane reactor does not inhibit this side reaction. However, as more ethylbenzene converts to styrene (due to the decreased $\mathrm{H}_{2}$ pressure), this reaction becomes less competitive. The benzene yield in the membrane still increases but at a slower rate. The simulation results would vary, dependent upon the rate equations applied for the side reactions and possibly the existence of intraparticle mass transfer resistance.

Yield of Main Product. Figure 10 shows the styrene yield in the conventional and the hybrid system in the selected case study. After a packed bed reactor of $25 \mathrm{~cm}$ in length, the styrene yield reaches the maximum level, but benzene and toluene do not. Ethylbenzene is continuously consumed in the second stage by the generation of benzene and toluene. This results in the reduction of ethylbenzene partial pressure, which promotes the reversed reaction of styrene to ethylbenzene. Consequently, the styrene yield in the second stage decreases.

With an add-on membrane reactor, the styrene yield increases because (a) styrene generation (eq 1) is enhanced and (b) side reactions are inhibited or slowed down by the selective removal of $\mathrm{H}_{2}$. In this analysis, about $5 \%$ exceeds the limit determined by the thermodynamic equilibrium between ethylbenzene and styrene, and about $10 \%$ exceeds the yield of the second-stage packed bed. The enhancement of the styrene yield could be further improved by optimizing the operating conditions.

Pressure Effects on Membrane Reactors. Since no catalyst is packed on the shell side, the pressure drop is almost unchanged under the simulation conditions. The pressure drop along the tubular side is $\leq 10 \%$ of the total pressure for the packing density $\geq 0.5$. Its effect on the 
product yield is negligible according to the simulation.

\section{Summary}

The mathematical model discussed in the literature has been modified to include side reactions. The differential equations thus developed have been solved numerically. Through this model, membrane reactors demonstrate the possibility of improvement in product selectivities along with the increase in conversion. A hybrid membrane reactor system has been proposed to improve existing processes for ethylbenzene dehydrogenation. The product yield exceeding the equilibrium limitation for a packed bed reactor is demonstrated through mathematical simulation.

\section{Nomenclature}

$C s$ = inert purge ratio, defined in Table II

$C t=$ feed dilution ratio of inert to reactant, defined in Table II

$d=$ membrane thickness, $\mathrm{m}$

$D a=$ Damkohler number defined in Table II

$D_{\mathrm{p}}=$ diameter of catalyst, $\mathrm{m}$

$k, k_{i}=$ reaction rate constant, $i=1, \ldots, 6, \mathrm{~mol} /\left(\mathrm{m}^{3} \cdot \mathrm{s} \cdot \mathrm{Pa}{ }^{n}\right)$, where $n=1,2,3$ depending on rate equations

$K_{i}=$ effective Knudsen permeability, $i=\mathrm{EB}, \mathrm{ST}, \mathrm{TOL}, \ldots$, $\mathrm{mol} /\left(\mathbf{m}^{2} \cdot \mathbf{s} \cdot \mathrm{Pa}\right)$

$K_{\mathrm{p}}=$ thermodynamic equilibrium constant, $\mathrm{Pa}$

$\mathrm{L}=$ total reactor length, $\mathrm{m}$

$M_{i}=$ molecular weight, $i=\mathrm{EB}, \mathrm{ST}, \mathrm{TOL}, \ldots, \mathrm{g} / \mathrm{mol}$

$N_{i}=$ molar flux in axial direction of tube side, $i=\mathrm{EB}, \mathrm{ST}$, TOL, ..., $\mathrm{mol} /\left(\mathrm{m}^{2} \cdot \mathrm{s}\right)$

$N_{i}^{\prime}=$ molar flux in axial direction of shell side, $i=\mathrm{EB}, \mathrm{ST}$, TOL, ..., $\mathrm{mol} /\left(\mathrm{m}^{2} \cdot \mathrm{s}\right)$

$P_{i}=$ partial pressure in tube side, $i=\mathrm{EB}, \mathrm{ST}, \mathrm{TOL}, \ldots, \mathrm{Pa}$

$P_{i}^{\prime}=$ partial pressure in shell side, $i=\mathrm{EB}, \mathrm{ST}, \mathrm{TOL}, \ldots, \mathrm{Pa}$

$P r=$ pressure ratio of shell to tube side, defined in Table II

$P_{\mathrm{g}}=$ total pressure of shell side, $\mathrm{Pa}$

$P_{\mathrm{t}}=$ total pressure of tube side, $\mathrm{Pa}$

$R=$ gas constant $=8.313 \mathrm{~Pa} \cdot \mathrm{m}^{3} /(\mathrm{mol} \cdot \mathrm{K})$

$r=$ pore radius of membrane, $m$

$R_{1}=$ inside radius of membrane, $m$

$R_{2}=$ inside radius of reactor (i.e., shell radius), $\mathrm{m}$

$T=$ temperature, $\mathrm{K}$

$v_{2}=$ mixture linear velocity in tube side, $\mathrm{m} / \mathrm{s}$

$v_{z}^{\prime}=$ mixture linear velocity in shell side, $\mathrm{m} / \mathrm{s}$

$z=$ reactor length, $\mathrm{m}$

Greek Symbols

$\epsilon=$ porosity of packed catalyst in reactor

$\epsilon_{\mathrm{p}}=$ porosity of membrane $\tau=$ tortuosity of membrane

$\rho=$ density of mixture, $\mathrm{kg} / \mathrm{m}^{3}$

$\mu=$ viscosity of mixture, $\mathrm{N} \cdot \mathrm{s} / \mathrm{m}^{2}$ or $10 \mathrm{P}$

$\Delta=$ defined in Table II

Registry No. EtPh, 100-41-4; $\mathrm{PhCH}=\mathrm{CH}_{2}, 100-42-5 ; \mathrm{C}_{6} \mathrm{H}_{6}$, 71-43-2; $\mathrm{MePh}, 108-88-3$.

\section{Literature Cited}

Bird, R. B.; Stewart, W. E.; Lightfoot, E. N. Transport Phenomena; Wiley: New York, 1960; pp 51 and 200.

Clough, D. E.; Ramirez, W. F. Mathematical Modeling and Optimization of the Dehydrogenation of Ethylbenzene to Form Styrene. AIChE J. 1976, 22 (6), 1097.

Itoh, N. A. Membrane Reactor Using Palladium. AIChE J. 1987, 33 (9), 1576.

Itoh, N.; Govind, R. Development of a Novel Oxidative Palladium Membrane Reactor. AIChE Symp. Ser. 1989a, 85 (No. 268), 10.

Itoh, N.; Govind, R. Combined Oxidation and Dehydrogenation in a Palladium Membrane Reactor. Ind. Eng. Chem. Res. 1989b, 28, 1554.

Itoh, N.; Shindo, Y.; Hakuta, T.; Yoshitome, H. Enhanced Catalytic Decomposition of $\mathrm{HI}$ by Using A Microporous Membrane. Int. J. Hydrogen Energy 1984, 9 (10), 835.

Itoh, N.; Shindo, Y.; Haraya, K.; Obata, K.; Hakuta, T.; Yoshitome, H. Simulation of a Reaction Accompanied by Separation. Int. Chem. Eng. 1985, 21 (1), 138.

Mohan, K.; Govind, R. Analysis of a Cocurrent Membrane Reactor. AIChE J. 1986, 32 (12), 2083.

Mohan, K.; Govind, R. Studies on a Membrane Reactor. Sep. Sci. Technol. 1988a, 23 (12\&13), 1715.

Mohan, K.; Govind, R. Analysis of Equilibrium Shift in Isothermal Reactor with a Permselective Wall. AIChE J. 1988b, 34 (9), 1493.

Mohan, K.; Govind, R. Effect of Temperature on Equilibrium Shift in Reactors with a Permselective Wall. Ind. Eng. Chem. Res. 1988 c, 27, 2064.

Reid, R. B.; Prausnitz, J. M.; Poling, B. E. The Properties of Gases \& Liquids; McGraw-Hill: New York, 1987; pp 397-411.

Sheel, J. G. P.; Crowe, C. M. Simulation and Optimization of an Existing Ethylbenzene Dehydrogenation Reactor. Can. J. Chem. Eng. 1969, 47, 183.

Sheppard, C. M.; Maier, E. D. Ethylbenzene Dehydrogenation Reactor Model. Ind. Eng. Chem. Process Res. Dev. 1986, 25, 207.

Sun, Y.; Khang, S. Catalytic Membrane for Simultaneous Chemical Reaction and Separation Applied to a Dehydrogenation Reaction. Ind. Eng. Chem. Res. 1988, 27, 1136.

Sun Y.-M.; Khang, S.-J. A Catalytic Membrane Reactor: Its Performance in Comparison with Other Types of Reactors. Ind. Eng. Chem. Res. 1990, 29, 232.

Wenner, R. R.; Dybdal, E. C. Catalytic Dehydrogenation of Ethylbenzene. Chem. Eng. Prog. 1948, 44 (4), 275.

Received for review March 22, 1991

Revised manuscript received September 3, 1991 Accepted September 13, 1991 